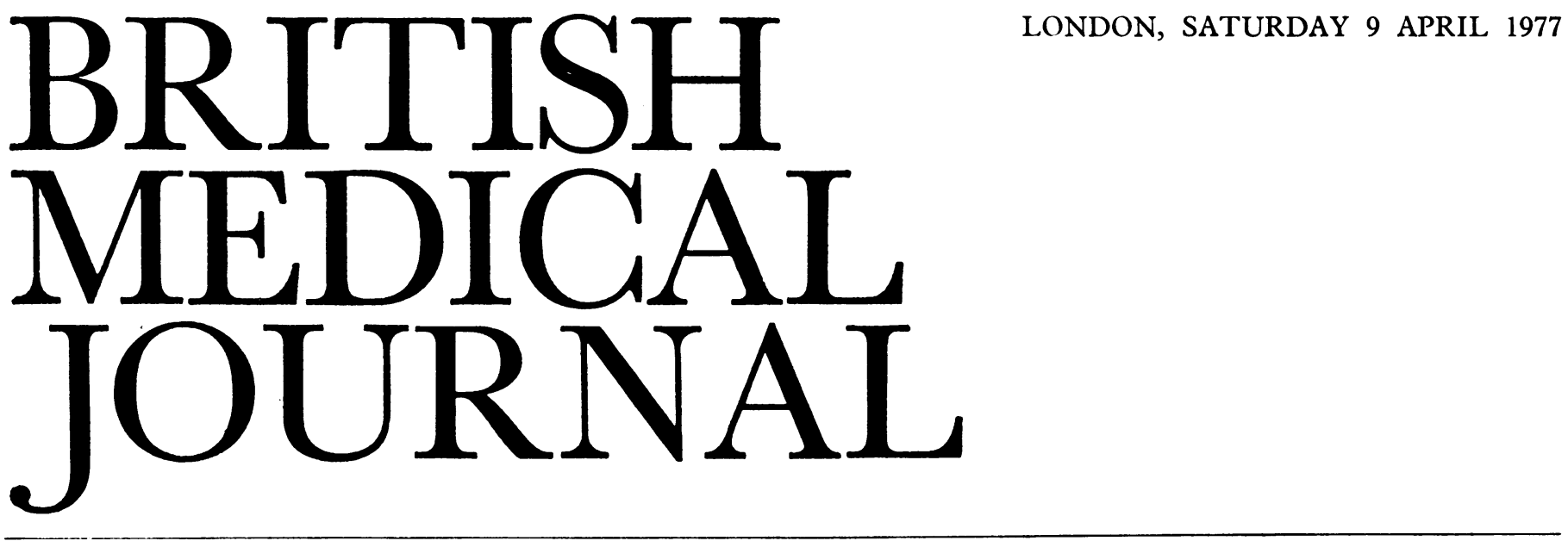

As long ago as 1933 streptococci were found to produce a substance which can lyse fibrin. ${ }^{1}$ Nearly 20 years ago this material, streptokinase, was shown, quite convincingly, to lyse clots in the human circulation. ${ }^{2}$ Yet today the place of streptokinase in treatment is still controversial; and the lack of generally accepted indications for its use argues that it is likely to remain of very restricted value in therapeutics.

Streptokinase acts by converting plasminogen to the active proteolytic enzyme, plasmin. The complex formed by the interaction of streptokinase with plasminogen has its greatest activity when the two substances are present in a one-to-one molar ratio. Formation of: the complex changes the plasminogen molecule by exposing an active catalytic site, giving activator activity to the whole complex. ${ }^{3}$ The plasminogen in the complex is converted to plasmin, and this streptokinaseplasmin complex also has activator activity. ${ }^{3}$

Plasmin is formed principally from non-complexed plasminogen by proteolytic cleavage of a single arginyl-valine bond. ${ }^{4}$ The streptokinase in the complex is degraded with progressive loss of activity." Two proactivators in human and bovine plasma may also be activated by streptokinase to produce plasmin from plasminogen, ${ }^{6}$ but it is not clear whether this pathway is important in therapeutic thrombolysis.

Dissolution of thrombus probably results from endogenous lysis caused by the formation of plasmin by the activator complex from plasminogen ${ }^{7}$ or by action of the activator ${ }^{8}$; both are incorporated into the thrombus during clotting. The alternative concept of exogenous lysis proposes that plasmin is released from a complex with antiplasmin near the thrombus owing to the strong affinity of plasmin for fibrin. ${ }^{9}$ Experimentally, however, exogenous lysis is feeble, thrombus lysing only slowly in solutions of pure plasmin. ${ }^{10}$ So the rationale behind streptokinase treatment is to produce activator activity with only limited release of free plasmin into the circulation. The methods used to achieve this balance and to monitor streptokinase treatment have been reviewed recently. ${ }^{11}$

Streptokinase has been tried in many clinical conditions with convincing evidence of benefit in few. The clearest indications are in the venous circulation-perhaps not surprisingly, since the venous thrombus most closely resembles the test tube clot. Controlled clinical trials have shown that streptokinase dissolves extensive deep venous thrombi more often and much more completely than other drugs. ${ }^{12-15}$ While this may be irrelevant to the subsequent incidence of pulmonary embolism, it is the form of treatment most likely to preserve the function of the deep venous valves. ${ }^{16}$ Destruction of the valves is probably the main cause of the postphlebitic syndrome-a chronically bloated limb prone to stasis ulceration. Long-term follow-up of patients with deep venous thrombosis suggests that streptokinase treatment reduces the number of patients with residual swelling and aching of the limb. ${ }^{17}$ A strong case can therefore be advanced for this treatment in younger patients in whom massive deep venous thrombosis extends above the knee.

The case for giving streptokinase after pulmonary embolism has occurred is less clear. Effective treatment must achieve one of three objectives: a reduction in mortality, a reduction in the period of incapacity, or an improvement in the longterm functional result. There is no clear evidence that treatment with streptokinase attains any of these objectives. Its use in patients with acute massive pulmonary embolism accelerates clearance of emboli from the pulmonary circulation and improves right heart function more rapidly than when heparin is given, ${ }^{18}$ though some patients may still require embolectomy. ${ }^{19}$ But most patients who are going to die will do so before any treatment can be given. The National Heart and Lung Institute Pulmonary Embolism Study showed that thrombolytic treatment had no real advantage over heparin in clearance of the lung scan six months after the acute event. ${ }^{20}$ Streptokinase treatment should therefore be reserved for the few patients who have acute massive pulmonary embolism with obstructed right-heart outflow but who do not appear to require surgical embolectomy to prevent impending death. Should a pregnant patient near term fall into this category streptokinase may be used successfully. ${ }^{21}$

A recent controlled clinical trial showed that prognosis in central retinal vein occlusion may be marginally improved by streptokinase treatment. ${ }^{22}$ Unfortunately, $15 \%$ of treated patients went blind in the affected eye as a result of vitreous haemorrhage, and the improvement in vision in the remainder, though statistically significant, was not impressive. Use of streptokinase should be restricted to the patient with healthy eyes and a transient thrombotic tendency-for example, a young woman taking an oral contraceptive-or to the patient already blind in one eye, in whom the hope of saving some sight may justify the risk.

The great hope for thrombolytic treatment has been that it might be possible to reduce morbidity and mortality from myocardial infarction by limiting the size of the infarct as a result of improved blood flow to areas of injury near the infarct. Streptokinase might achieve this by lysing incompletely obstructing thrombus, preventing further distal propagation 
of thrombus, and reducing blood viscosity. Many trials of variable quality have been completed, but, disappointingly, the three studies in coronary care units have shown that use of streptokinase within 24 hours of the acute event has no effect on either morbidity or mortality. ${ }^{23-25}$ There are almost insuperable logistic problems in completing a trial large enough to show convincingly even a $25 \%$ reduction in mortality from myocardial infarction. ${ }^{26}$ The story of anticoagulant therapy in myocardial infarction ${ }^{27}$ indicates the need for great caution until, if ever, the place of streptokinase is validated by large-scale trials of irreproachable experimental design.

Similarly, results with streptokinase have been disappointing in occlusion of peripheral arteries. In acute arterial obstruction surgery is likely to be more successful and more reliable ${ }^{28}$; and, again, the results of treatment with streptokinase of chronically occluded vessels have been generally unsatisfactory. ${ }^{29}$ Hence probably streptokinase has only a small part to play-in treating patients unfit for surgery in whom arterial obstruction is incomplete. A few patients with occlusion of the retinal artery may attain improved vision from thrombolysis, ${ }^{30}$ but properly controlled studies have not been carried out.

There is a mass of uncontrolled evidence from compilations of case reports, recently reviewed, ${ }^{31}$ in which streptokinase has been used successfully to treat occluded arteriovenous shunts, priapism, disseminated intravascular coagulation, and thrombosed valve prostheses. There are no reports of its use in cerebrovascular disease, but experience with urokinase in treating established stroke was not encouraging. ${ }^{32}$ Miscellaneous uses include diagnosis of deep venous thrombosis by streptokinase coupled to 99 -technetium, ${ }^{33}$ but this method has no obvious advantage over standard isotope diagnostic methods.

Haemorrhage is the only serious complication of treatment with streptokinase, but it may be massive and difficult to control-a compelling reason for restriction of streptokinase to conditions where benefit has been clearly established. At the moment these are few. Further developments, such as combining streptokinase with plasminogen, ${ }^{34}$ may improve results, but it seems more likely that streptokinase will remain a valuable drug for use in only a few carefully selected patients.

1 Tillet, W S, and Garner, R L, fournal of Experimental Medicine, 1933, 58, 485.

2 Johnson, A J, and McCarty, W R, fournal of Clinical Investigation, 1959, 38, 1627.

${ }^{3}$ Reddy, K N N, and Markus, G, fournal of Biological Chemistry, 1972, 247, 1683.

${ }^{4}$ Summaria, L, Hsieh, B, and Robbins, K C, fournal of Biological Chemistry, 1967, 242, 4279.

5 Siefring, G E, and Castellino, F J, fournal of Biological Chemistry, 1976, 251, 3913.

6 Takada, A, Takada, Y, and Ambrus, L, Thrombosis et Diathesis Haemorrhagica, 1971, suppl 47, 37.

7 Alkjaersig, N, Fletcher, A P, and Sherry, S, fournal of Clinical Investigation, 1959, 38, 1086.

${ }^{8}$ Chesterman, C N, Allington, M J, and Sharp, A A, Nature (New Biology), 1972, 238, 15.

${ }^{9}$ Ambrus, C M, and Markus, G, American fournal of Physiology, 1960, 199, 491.

${ }^{10}$ Deutsch, E, Thrombosis et Diathesis Haemorrhagica, 1971, suppl 47, 145.

11 Flute, P T, British Fournal of Hospital Medicine, 1976, 16, 135.

12 Kakkar, V V, et al, British Medical fournal, 1969, 1, 806.

13 Duckert, F, et al, British Medical fournal, 1975, 1, 479.

14 Tsapogas, M G, et al, Surgery, 1973, 74, 973.

15 Tibbutt, D A, et al, British fournal of Haematology, 1974, 27, 407.

16 Kakkar, V V, et al, British Medical fournal, 1969, 1, 810.

17 Johansson, E, Ericson, K, and Zetterquist, S, Acta Medica Scandinavica, 1976, 199, 89.

${ }_{18}$ Miller, G A H, et al, British Medical fournal, 1971, 2, 681.

19 Tibbutt, D A, et al, British Medical fournal, 1974, 1, 343.

20 Urokinase Pulmonary Embolism Trial Study Group, fournal of the American Medical Association, 1970, 214, 2163.

${ }^{21}$ Hall, R J C, et al, British Medical fournal, 1972, 4, 647.
${ }^{22}$ Kohner, E M, et al, British Medical fournal, 1976, 1, 550.

${ }^{23}$ Dioguardi, N, et al, Lancet, 1971, 2, 891.

${ }_{24}$ Bett, J H N, et al, Lancet, 1973, 1, 57.

${ }^{25}$ Aber, C P, et al, British Medical fournal, 1976, 2, 1100.

26 Verstraete, M, Thrombosis et Diathesis Haemorrhagica, 1973, suppl 56, 227.

27 Gifford, R H, and Feinstein, A R, New England Fournal of Medicine, 1969, 280, 351 .

${ }^{28}$ Persson, A V, Thompson, J E, and Patman, R D, Archives of Surgery, 1973, 107, 779.

29 Verstraete, M, Vermylen, J, and Donati, M B, Annals of Internal Medicine $1971,74,377$.

${ }^{30}$ Hawkey, C, and Howell, M, Fournal of Clinical Pathology, 1964, 17, 363.

${ }^{31}$ Brogden, R N, Speight, T M, and Avery, G S, Drugs, 1973, 5, 357.

32 Fletcher, A P, et al, Stroke, 1976, 7, 135.

${ }^{33}$ Kempi, V, van der Linden, W, and von Schéele, C, British Medical fournal, 1974, 4, 748.

${ }^{34}$ Kakkar, V V, Sagar, S, and Lewis, M, Lancet, 1975, 2, 674.

\section{Doctor in court}

Traditionally medical men are reluctant to appear as witnesses in a court of law. There are, of course, a few doctors who appear so regularly that such inhibitions have long been overcome: the forensic pathologist often accepts the coroner's court as his equivalent of the surgeon's operating theatre and, indeed, may have "lists" on certain days of the week. Again, the police surgeon usually has more than a nodding acquaintance with both magistrate's and crown courts, though this has declined since the introduction of the breathalyser and blood tests.

Even so, most doctors view attendance at court with emotions ranging from sheer impatience to abject terror. The impatience-and sometimes exasperation-is born of the knowledge that time will be wasted; surgeries and clinics may have to be abandoned; and possibly locums will have to be paid. Yet, while doctors may believe that the courts delight in keeping them hanging about for days in dingy waiting rooms and draughty corridors, in actual fact the medical witness gets preferment on a regal scale over the lay public.

Apart from the inconvenience and frustration, the culmination of anxiety arrives when the doctor steps into the witness box and takes the oath. The inexperienced medical witness frequently feels that he is there to be ridiculed, pilloried, or abused, though in these enlightened days this rarely happens. Thankfully, the days of the hectoring, bullying advocate have passed, and the cut and thrust of counsel and witness are now conducted on a most gentlemanly level-though admittedly this does not prevent the astute lawyer from running the doctor through with the rapier of his tongue when the occasion demands.

Some brief tips might help to ward off this legal evil eye. In forensic circles there has long been a proverb that the doctor in court should "dress up, stand up, speak up, and shut up." To "dress up" means appearing in court looking something like the traditional public image of a doctor. A high court judge is not usually very amused at being confronted with a houseman looking like an escapee from Top of the Pops. When a house officer appeared at an inquest attired in a loud plaid lumber-jacket and a large stetson the rather testy coroner told him to go home and come back in attire more in conformity with the presence of bereaved relatives-and further indicated that no fee would be forthcoming.

To "stand up" is an obvious piece of advice and one that may sometimes add an illusory air of confidence when the actual material of the evidence is not too convincing. The doctor who does not "speak up" but mumbles inaudible polysyllabic incantations into his notes rapidly arouses the ire 